\title{
Application of Blended Learning Method to the Course of English Reading
}

\author{
Guangping Sun \\ School of Foreign Language Studies \\ Ningbo Institute of Technology \\ Zhejiang University \\ Ningbo, China
}

\begin{abstract}
With the help of advanced technology, blended learning is becoming more and more popular in modern education. In this paper, the writer tried to apply blended learning model to her teaching practice. Her empirical research showed the effectiveness and efficiency of blended learning.
\end{abstract}

\section{Keywords—blended learning; method; English reading}

\section{INTRODUCTION}

Blended learning is based on the traditional learning mode, supplemented by online learning mode. The combination of the two can fully reflect the advantages of each of the two, and complement their shortcomings. In this complementary learning mode, teachers' function as the main teaching guide has not been weakened; on the contrary, during the blended learning class, teachers can guide, inspire, and monitor the students; at the same time, students' role as the subject of learning is still enhanced. Furthermore, through the online and offline learning, students' initiative and the enthusiasm and creativity can be further strengthened.

The term "blended learning" was first put forward in 2000 by Paul Myers [1]. In 2006, Gramham defined "blended learning" as "learning systems that "combine faceto-face instruction with computer mediated instruction"[2].

Blended learning can be used to make up the deficiency of MOOC (a massive online course), such as the monotonous presentation, lacking of targeted guidance, unable to monitor the students' online time, their online participation, which lead to the ineffective depth-leaning, thus blended learning has been welcomed by the educational circles worldwide.

The incorporation of information technology and class projects have improved the communication between teachers and part-time students and provided the latter a good opportunity to evaluate their comprehension of course material with the aid of "computer-based qualitative and quantitative assessment modules" [3].

\section{RESEARCH REVIEW}

Many scholars have applied the blended teaching mode into their teaching practice and achieved obvious achievements. The achievements can be categorized as the following aspects.

First, in terms of application objects, the present researches showed that blended learning has been applied in different levels and disciplines in teaching.

Second, in terms of the implementation of blended learning, means of network learning, e-learning and information and communication technology are the modes mostly used in blended learning research.

Third, the popular research trend of blended learning is on the construction of blended learning, research on teaching strategies and learning strategies under the context of blended learning.

Rowe argued that in the modern education, educators should consider the opportunity of using technology to strengthen the students' communicative skills and provide them richer and more meaningful platform, so that the students can construct their knowledge system. He also argued that by applying new technology to make students to walk out of the classroom and participate in shared learning experiences, the educators can provide the students chances to promote their formats of thinking and help them to cope with well in the real, but complex world situations. Rowe suggested a new blended learning method, which is, combining authentic learning as a guiding framework with Google Drive as an online platform. They found that this blended learning method helped the students in their learning practice, changed the power relationships in the classroom and most important of all, developed students' critical thinking abilities to knowledge and improved their understanding of authority [4].

Based on the analysis of 205 master's theses and doctoral dissertations in the field of blended learning published in the recent 10 years, Drysdale found the research trends and presented them in terms of the growth and context of blended learning research. He analyzes those research trends from the following aspects. One is from the methodological trends. He has found that when analyzing the research data, the following methods, such as qualitative method, inferential statistics method, descriptive statistics method and combined methods are the mainly used methods. As to the research topics, he summed up nine main topics, that is, 
learner outcomes, dispositions, instructional design, interaction, comparison, demographics, technology, professional development and other. His research laid a foundation to the future research in the field of blended learning research and highlights the opportunities for the research to continue growing.

He summarized the development trend of blended learning research in terms of quantitative change, research background, organization form, method, theme and theoretical framework. The research findings show that blended learning practice is developing rapidly, but there has been no in-depth research on theory. The future research direction will focus on learners' motivation and participation as well as institutional policy aspects [5].

Halverson and other researchers used Google scholar to search the publications relevant to blended learning from 2000 to 2010 . They tried to find the most cited publications, and to analyze blended learning from three aspects: theoretical framework, research topics and the theoretical framework. There are some findings in their research. One is that globally, very few academic articles were published in the core distance education journals. Most relevant academic articles were published in the journals related to educational technology and technology integration. The second finding is most research on blended learning has focused on definitions, models and the potential of blended learning, rather than on empirical work.

They argued that researchers should shift their attention from this preliminary stage beyond to the more depth research, such as to the research of pedagogy and design, etc., trying to answer the provoking questions, for example, what are the most effective blended learning strategies for specific contexts?[6]

Wright did a survey about how undergraduate EFL students' think about online lessons. The research found that most students preferred face-to-face classroom teaching, for such method can motivate their learning interest because of the better understanding, more interaction with teachers and peers, and much input from the teachers. Some students value the online lessons because such method can provide flexibility, convenience and speedy study. [7]

Wang used the content analysis method to analyze systematically academic papers relevant to the research of blended learning, which were published during 2003 to 2012. They focused the research on the following four aspects: the number of papers, sources of papers, research groups and contents. [8]

From the perspective of research methods, the commonest methods being applied in blended learning research are constructive theory/ model method and hybrid research method, followed by the descriptive statistical analysis and qualitative research methods. Applying the hybrid research method, the scholars can combine the empirical and non-empirical methods together to achieve the most benefit from their class practice.

\section{APPLYING BLENDED LEARNING METHOD IN THE COURSE OF ENGLISH READING}

Based on the theoretical framework and the empirical practice in blended learning, the author of this paper tried to apply blended learning method to the course of English Reading, a compulsory course for English majors in most Chinese universities, in order to improve the English majors' English reading skills and improve their English proficiency.

In teaching English Reading, the teacher combined the traditional face-to-face lectures and online teaching with the help of modern network technology to make the course study meet the students' individual needs. With the help of the function of the QQ group, besides the classroom learning, the teacher can monitor and manage the students' the online learning, so as to improve students' reading skills, expand the cultivation of intercultural communicative competence and knowledge as well. During the autonomous learning training, students' various abilities, such as team cooperation ability, text analysis ability, independent thinking ability and critical thinking ability can be improved greatly.

The followings are what the blended learning method has been done in the course the English Reading.

Course book: A New English Reading Course, published by Shanghai Foreign Language Education Press as the designated textbook. The teacher selected ten units from the textbook as the contents for classroom learning, and arranged the corresponding after-school reading and online learning materials.

After class reading and online learning, the teaching function of QQ group was used as a tool to track students' learning process.

Finally, complete content and organizational editing before formatting. Please take note of the following items when proofreading spelling and grammar.

\section{METHODOLOGY}

The concrete construction of the mixed teaching method in English reading course is as follows.

\section{A. Online Learning Practice before Class}

Before class, the teacher uploaded PPT of the ten units and the articles about how to improve the important reading skills, such as how to skim and scan, so that the students can build up their reading skills for their further study. Materials for reading skills and PPTs relevant to Textbook helped the students to prepare for their lessons, so as to gain the greatest understanding in classroom teaching.

\section{B. Classroom Teaching in the Form of Face-to-face Teaching}

In the classroom teaching, the teacher, based on the curriculum content for each unit, combined with the reading skills which have been put to the website, showed the detailed analysis of English reading skills of skimming and scanning. After that, the teacher asked the students to use these two reading skills to read the whole passage for each 
unit, acquiring the main idea and recognizing the supporting evidence for the main idea. Then the teacher asked the students to analyze the text from the perspective of whole structure, understand how the writer illustrate the subject, how to layout, and finally how to support his idea with the convincing arguments or rich materials.

\section{Online Learning Practice after class}

The teacher used online learning practice after class to improve the students' self-learning ability and critical thinking ability, and expand the students' reading field of vision by using network the internet technology and resources based on the online learning

1) The expansion of extracurricular reading materials: It is well known that extensive reading is the most fundamental way to improve students' reading ability. However, due to the limitation of class hours, in the traditional classroom teaching, it was not possible for the teacher to assign many reading materials for students to read. With the help of online resources, the teacher can make up such reading deficiency by uploading the complementary reading materials to the online learning website. After reading the complementary readings online, the students were asked to post the summary for the reading materials, write down their reflections for the topics and design some appropriate reading comprehension questions for other students to finish. All these practices were used to improve the students' reading comprehension and their critical thinking.

Another online task was that the students should form study groups. Each study group should select materials relevant to the topic of each unit from the internet or other resources upload these selected extracurricular reading materials to the online learning website. Such extracurricular reading materials can enlarge the students' reading vision and improve their reading interests.

2) The expansion of audiovisual resources after extracurricular activity: On the basis of students' independent choice of reading materials and the supplementary materials provided by teachers, related audio-visual resources were also uploaded to make students' learning process richer and interesting.

For example, the theme of Unit 7 is about Sports. In order to enrich the reading comprehension and promote the students' interest in learning the materials, the video of the Opening Ceremony of Olympic Games, 2016 was uploaded to the online learning website, so that the students can learn English in the audio-visual environment and enhance their understanding of the theme.

Another example is Unit 15. This unit is about fiction. The novel Pride and Prejudice is well known all over the world and was made in films. The teacher shared the link of the film Pride and Prejudice to the online learning website for the students to appreciate the film, to improve their reading interest, and to stimulate the students' motivation in learning English in the authentic English cultural.
3) Final presentation for the blended learning: At the end of the term, the students were asked to present what they had learned in front of the whole class. The purpose of the presentation is to cultivate the students' independency, innovation and self-reflection. The presentation was finished by the teamwork. Before the presentation, the team members should choose one unit from the 10 units as the research subject, then they should collect the materials relevant to the topic of the unit, read the materials thoroughly, discuss with the team member, doing in-depth reading, analyzing the materials. After that, the team members should write down the process of their group discussion, their understanding and their reflections. All these should be presented at the end of the term

\section{CONCLUSION}

After the practice of blended learning method, the students' reading comprehension has been improved greatly, compared with the traditional classroom teaching. The blended learning method, combined with the advantages of classroom teaching and the online learning. During the classroom teaching, the students' can have a clear understanding of the course content, a close relationship with the teacher by the face-to-face teaching. Hence, their psychological needs can be met. At the same time, online learning can provide the students rich materials, timely feedback, and the study place and study time can be very flexible. All of these provided the students ample support which led a happy, relaxed, but full learning process.

\section{REFERENCES}

[1] A. Kitchenham, "Blended learning across disciplines: models for implementation", Information Science Reference, Foreword, xiii, 2011.

[2] C.J.Bonk, and C.R. Graham, "The handbook of blended learning environments: Global perspectives", Local Designs. San Francisco: Jossey - Bass/Pfeiffer. 2006,p. 5.

[3] S.Alexander, and McKenzie, J. "An Evaluation of Information Technology Projects for University Learning". Canberra, Australia: Committee for University Teaching and Staff Development and the Department of Employment, Education, Training and Youth Affairs, 1998.

[4] M. Rowe, et al. "Using Google Drive to Facilitate a Blended Approach to Authentic Learning", British Journal of Educational Technology, vol. 44, p594-606, July 2013.

[5] J. S. Drysdale, C. R. Graham, and K. J. Spring, et al.(2013). “An Analysis of Research Trends in Dissertations and Theses Studying Blended Learning". The Internet and Higher Education, Vol. 17,pp 90-100, 2013.

[6] L. R. Halverson, C. R.Graham, and Spring, K. J. et al.."An Analysis of High Impact Scholarship and Publication Trends in Blended Learning", Distance Education, vol 33,pp 381-413, Nov. 2012.

[7] B. M. Wright, "Blended Learning: Student Perception of Face-toFace and Online EFL Lessons", Indonesian Journal of Applied Linguistics, Vol. 7, pp. 64-71,May 2017.

[8] Wang Guohua, et al, "An Analysis in Chinese Blended Learning". Distance education in China, vol. 2, pp25-31, Feb. 2015. 